\title{
İSTANBUL'UN İLÇELERİNİN AFET YÖNETİMİ AÇISINDAN ÖNEM AĞIRLIKLARININ ANALİTİK HİYERARŞİ SÜRECİ KULLANILARAK BELİRLENMESİ
}

\author{
Abdullah Korkut ÜSTÜN ${ }^{1}$, Ahmet Sermet ANAGÜN ${ }^{2}$ \\ ${ }^{1}$ Aksaray Üniversitesi, Mühendislik Fakültesi, Endüstri Mühendisliği Bölümü, 68100, Aksaray \\ ${ }^{2}$ Eskişehir Osmangazi Üniversitesi, Müh. Mim. Fak., Endüstri Mühendisliği Böl., 26480, Eskişehir \\ korkut.ustun@gmail.com, sanagun@ogu.edu.tr
}

(Geliş/Received: 19.12.2014; Kabul/Accepted: 05.12.2015)

\begin{abstract}
Özet
İstanbul tarih boyunca birçok deprem yaşamıştır ve önümüzdeki 30 yıl içerisinde de yüzde 65 ihtimalle yıkıcı bir deprem yaşaması beklenen bir şehirdir. Yaklaşan bu afet riski, afet yönetim sisteminde yapılacak önemli değişiklikler ile azaltılabilir. Bu çalışmada, sosyo-ekonomik kriterler, bina yapısı kriterleri, coğrafi ve jeolojik özellikler kriterleri ve altyapı kriterleri ile bu kriterlerin alt kriterleri Analitik Hiyerarşi Süreci (AHS) yöntemi kullanılarak İstanbul'un ilçeleri incelenmiş ve her bir kriter grubu için ve bütünsel olarak risk haritaları oluş̧urmuştur. Yapılan bu çalışma ile karar vericiler için iyileştirme yapılacak alanların tespiti konusunda önemli ipuçları elde edilmiştir. Çalışmanın sonuçları afet yönetimi faaliyetleri konusundaki uygulayıcılar içinde bir rehber olarak kullanilabilir.
\end{abstract}

Anahtar Kelimeler: Afet yönetimi, çok ölçütlü karar verme, analitik hiyerarşi süreci, risk göstergeleri, bina önem indeksi, afet risk haritaları

\section{DETERMINATION OF IMPORTANCE WEIGHTS OF ISTANBUL'S DISTRICTS USING ANALYTIC HIERARCHY PROCESS}

\begin{abstract}
Istanbul is an earthquake prone city and has experienced many earthquakes throughout history. Also, Istanbul is threatened by a $65 \%$ probability of a devastating earthquake in the next 30 years. In order to reduce the disaster risk in Istanbul, structure of disaster management must be strengthened. In this study, importance weights of districts of Istanbul are determined and risk maps are generated by Analytic Hierarchy Process (AHP) including criteria of socio-economic, building, structure, geographical and geological features, and infrastructure and subcriteria of these criteria. We consider that results of this study can provide a decision support framework for policy makers to reflect critically on possible risk mitigation plans. The results would be used as guidance for practitioners.
\end{abstract}

Keywords: Disaster management, multi criteria decision making, analytic hierarchy process, risk indicators, building importance index, disaster risk maps

\section{GIRIŞ (INTRODUCTION)}

İstanbul, 15 milyona yaklaşan nüfusu, sürekli büyüyen dinamik ekonomisi, tarihi ve turistik önemiyle, Türkiye'nin en önemli kenti, dünyanın da en önemli merkezlerinden biridir. Hızlı nüfus artışı, sanayileşme ve kentleşme, küçük kentlerde ve kırsal bölgelerdeki işsizlik ve insanların daha iyi eğitim alabilme isteği gibi sebeplerin de etkisiyle İstanbul son yıllarda çok yoğun bir göç almıştır. Bu durum ise şehirde yoğun ve kontrolsüz bir yapılaşma baskısını doğurmuştur. Denetimsiz, kaçak ve sağliksız konutlar şehrin hemen her bölgesini sarmış bulunmaktadır. Bazı bölgelerde kaçak şehirler dahi oluşmuştur. $\mathrm{Bu}$ düzensizlik ve kargaşa ortamı herhangi bir afet durumunda krizi daha da artıran bir etken olarak gözükmektedir [1]. Bütün bu olumsuz unsurların yanında, İstanbul çok önemli bir fay hattının 
yakınında bulunmaktadır. Kuzey Anadolu Fayı Türkiye'nin kuzey kesimi boyunca uzanır. Tarihte birçok yıkıcı deprem bu fay üzerinde meydana gelmiştir. Kuzey Anadolu Fayı'nın Marmara Denizi'ndeki uzantısı, İzmit Körfezi çıkışından Saros Körfezi'ne doğru uzanmaktadır. Tespit edilen bu fayın uzunluğu yaklaşık 200 kilometredir. Bu fayda meydana gelebilecek bir depremin büyüklüğünün ise 7,7 şiddetinde olabileceği öngörülmektedir. Bu büyüklükte bir depremin 30 yıl içerisinde meydana gelmesi olasılığı yüzde altmış beş olarak değerlendirilmektedir [2]. Ayrıca, deprem senaryolarında, İstanbul'da yaklaşık 160.000 hasarlı, 320.000 bina orta hasarl1, 520.000 binanın ise az hasarlı duruma gireceği ortaya konulmuştur. Bu veriler 1şığında 70.000 civarında kişinin öleceği ve 170.000 kişinin yaralı olarak depremden kurtulacağ1, yaklaşık beş milyon kişinin barınma problemi yaşayacağ1 öngörülmektedir[1]. Afet yönetimi problemlerine yöneylem araştırması, istatistik gibi sayısal yöntemleri öne çıkaran metotlarla çözümler arayan çalışmalar literatürde çok az rastlanılmıştır. Genellikle afet yönetimi sosyal ve beşeri bilimlerin konusu olarak araştırmalarda öne çıkmıştır. Shah ve arkadaşları [3] bina güçlendirmeleri en uygun yere yapılmasını ve güçlendirme yatırımından en fazla faydayı sağlayacak bir tamsayılı matematiksel model ortaya koymuşlardır. Dodo ve arkadaşları [4] Los Angeles şehrindeki bina güçlendirmeleri en uygun ve az maliyetle yapılmasını sağlayacak bir doğrusal programlama modeli önermişler. $\mathrm{Bu}$ alandaki diğer önemli bir çalışmada Vaziri ve arkadaşlarının [5] Tahran şehrindeki bina güçlendirmelerini en iyileyen modelleridir. Üstün ve Barbarosoğlu [6] 1999 Marmara ve Düzce depremlerinden sonra afet zararını azaltma çalışmalarının etkinliğini veri zarflama analizi metoduyla belirlemişlerdir. Üstün ve Anagün [7] ise beklenen büyük İstanbul depremindeki zararları en aza indirecek çok amaçlı bir matematiksel model önermişler ve bu modelin çözüm yöntemlerini tartışmışlardır Şehirlerin afetler karşısında zarar görebilirliğini ölçen bir metot üzerine araştırmacılar arasında bir uzlaşma sağlanabilmiş değildir [8]. Bu çalışmada Analitik Hiyerarşi Süreci (AHS) yöntemi şehirlerin afetler karşısında zarar görebilirliğini ölçen bir yöntem olarak kullanılmıştır. İncelenen literatürde afet yönetimi problemlerine AHS gibi çok nitelikli karar verme yöntemleri kullanılarak çözüm arayan çalışmalara çok fazla rastlanılmamıştır. Ayalev ve arkadaşları [9] toprak kaymalarına neden olabilecek faktörleri AHS ve lojistik regresyon yardımıyla ağırlıklandırmışlardır. Ercanoglu ve arkadaşları [10] ise Türkiye'nin Karadeniz bölgesindeki toprak kaymalarını AHS ve yapay sinir ağları yardımıyla incelemiştir. Wang ve arkadaşları [11] sellerin zarar verebilirliğini hesapladıkları çalışmalarından fuzzy AHS yönteminden faydalanmışlardır. Levy [12] ise sel riskinin yönetimi ve planlanmasında Analitik Serim Süreci (ASS) yöntemini kullanmıştır. Armas [8] ise Romanya'nın Bükreş kenti için yaptığı risk değerlendirme çalışmasında, AHS'nin ikili karşılaştırma mantığını kullanmıştır. $\mathrm{Bu}$ ikili karşılaştırma oranlarıyla Bükreş'in bina stoku, çevresel, sosyoekonomik ve bunların toplamını oluşturacak şekilde risk haritasını çıkarmıştır. AHS yöntemi her ne kadar afet yönetimi problemlerinde sıklıkla uygulanmasa da, en uygun işletme yeri seçiminde [13, 14], yatırım kararları ve üretilecek ürünün belirlenmesi $[15,16]$, tedarikçi seçiminde [1719] ve risk yönetimi [20] gibi alanlarda uygulamaları bulunmaktadır. $\mathrm{Bu}$ çalışmada ise önceki çalışmalardan farklı olarak İstanbul'un ilçelerinin afet yönetimi açısından önem ağırlıkları AHS yardımıyla bulunmuştur ve İstanbul ve ilçelerinin afetler karşısında zarar görebilirliği belirlenmiştir. Önerilen AHS yapısında, bina stoku, coğrafi ve jeolojik özellikler, altyapı ve sosyo-ekonomik kriterler ve bu kriterlerin alt kriterleri yer almaktadır. Çalışmayla İstanbul'un risk haritaları oluşturulmuştur. Böylelikle karar vericiler ve şehir plancıları için afet yönetim sisteminde özellikle de bina güçlendirmelerinde hangi bölgelere önem vermeleri gerektiği konusunda önemli ipuçları elde edilmiştir. Çalışma izleyen şekilde organize edilmiştir. Bölüm 2'de AHS yönteminin detayları verilmektedir. Bölüm 3'te önerilen model ve uygulama, Bölüm 4 ve 5'te ise sırasıyla sonuçlar ve tartışma ve sonuçların değerlendirmesi yer almaktadır.

\section{ANALITIK HIYYERARŞİ SÜRECİ (ANALYTIC HIERARCHY PROCESS)}

Çok nitelikli karar verme problemlerinde en sık kullanılan tekniklerden biri Analitik Hiyerarşi Sürecidir. AHS 1977 yılında Saaty [21] tarafindan karar verme problemlerin çözümü amaciyla geliştirilmiştir. $\mathrm{Bu}$ yöntemde temel prensip ölçütler, alt ölçütler ve seçenekler arasında bir hiyerarşik yap1 belirlemektir. Yöntemde insanların karar alırken içgüdüsel olarak uyguladığı, ölçüt, alt ölçüt seçeneklerin karşılıklı karşılaştırmalar ile kıyaslanması yapılmaktadır. Diğer bir ifadeyle karar vericiler öznel ve nesnel görüşlerini beraberce karar sürecine katabilirler [21]. Yöntemin teorik temelleri aşağıda bulunan dört aksiyoma dayanmaktadır [21]:

Aksiyom 2. 1 (karşılıklı olma): Eğer bir a kriteri b kriterine göre k kez daha önemli ise, b kriteri de a'ya göre $1 / \mathrm{k}$ kez daha önemlidir. $a_{i j}=\mathrm{k}$ ise $a_{j i}=1 / \mathrm{k}^{\prime}$ dir.

Aksiyom 2. 2 (homojenlik): Birbirinden çok farklı ve karşılaştırılması manasız olan elemanlar karşılaştırılamaz. Diğer bir ifadeyle iki özellik karşılaştırılırken biri diğerine sonsuz derecede tercih edilemez. Örneğin bir mum aleviyle güneş kıyaslanamaz. Tercihler birbirleriyle sınırlı bir ölçekle kıyaslanabilir olmalıdır. AHS'de kullanılan ölçek 1-9 aralığında olduğu için iki eleman arasındaki önem karş1laştırma değerleri de $1 / 9,1 / 8, \ldots, 1, \ldots, 7,8,9$ aralığında bir değer alacaktır. 
Aksiyom 2. 3 (bă̆ımsızlık): Bir seviye ile ilgili olarak verilen kararların alt ve diğer sevilerden bağımsız olmasına dayanmaktadır.

Aksiyom 2. 4 (beklenti): Karar problemi ve AHS'nin hiyerarşik yapısı oluşturulurken, karar vericilerin tüm beklentileri ve düşünceleri iyi analiz edilmelidir. Çünkü farklı alternatif ya da kriterler alınarak hiyerarşi oluşturulursa sonuç da değişsebilir. Bu yüzden hiyerarşinin ölçütler, alt ölçütler ve alternatifler karar vericinin beklentilerini karşılayacak şekilde dizayn edilmesi gerekmektedir. Aksi durumda karar yetersiz kalır.

AHS yönteminde karar problemi hiyerarşik bir yapıya dönüştürülür. Hiyerarşi oluşturulurken ilk önce seviyeler oluşturulur. Seviyeleri doğru sıralarla belirlemek önemli ölçüde yapıdaki elemanların doğru seçilmesine olanak sağlar. Hiyerarşide aynı seviyede bulunan elemanların birbirinden bağımsız oldukları varsayılır. İlk sırada amaç veya hedefler yer alırken ikinci seviyede kriterler (ölçütler) ve alt kriterler, son seviyede de alternatif kararlar yer almaktadır. Ancak bu ayrıştırmanın belirli bir düzeyi geçmemesi gerekmektedir. Genel kabul gören görüşe göre bir seviyede en fazla 7 elaman bulunmalıdır [21].

AHS uygulaması beş aşamadan oluşur. İlk aşama problemin tanımlanması, problem için amacın belirlenmesi ve değerlendirme kriterlerinin ve alt kriterlerinin tespit edilmesidir. Bu aşamada problemi etkileyen tüm kriterlerin belirlenebilmesi için anket başvurulabilir veya bu konuda uzman kişilerin görüşlerine danışılabilir. İkinci aşama kriter ve alt kriterlerin kendi aralarında önem derecelerinin belirlenmesi için ikili karşılaştırma matrisleri oluşturulmasıdır. $\mathrm{Bu}$ matrislerin oluşturulmasında, $\mathrm{n}$ kriterin olduğu varsayıldığında nxn boyutlu bir kare matris oluşur. $\mathrm{Bu}$ matrislerin köşegeni üzerindeki elemanları 1 değerini alırlar. Çünkü bu durumda ilgili kriter kendisi ile karşılaştırılmaktadır. Ölçütlerin karşılaştırılması konunun uzmanları tarafından yapılır ve ölçütlerin birbirlerine göre sahip oldukları önem Saaty tarafindan belirlenen ve üst sinır1 9 olan Tablo 1 deki önem skalası kullanılarak kiyaslanır. Karşılaştırmalar, karşılaştırma matrisinin tüm değerleri 1 olan köşegeninin üstünde kalan değerler için yapılır. Köşegenin altıda kalan bileşenler için ise $\mathrm{aji}=1 / \mathrm{a}_{\mathrm{ij}}$ formülü geçerli olur. İkili karşılaştırmalarda 1-9 ölçeği temel ölçek olarak seçilmiştir [21]. Bu karşılaştırma matrisi uzmanların grup olarak alacakları karar olabileceği gibi, her bir uzmandan ayrı ayrı alınacak sonuçların geometrik ortalaması alınarak da oluşturulabilir [21, 22]. AHS uygulamasında üçüncü aşama ise önem ağırlıklarının belirlenmesidir. Karşılaştırma matrisleri kullanılarak öncelik veya ağırlık vektörleri hesaplanır [22]. Sonraki aşama ise bu kıyaslamaların ne derece tutarlı olduğunun tespit edilmesidir. Yapılan karşılaştırmalarda objektif değerlendirmelerin yanı sıra sübjektif değerlendirmeler de yer aldığından karşılaştırmalardaki tutarlığın ölçülmesi gerekmektedir [21]. Elde edilen bu tutarlılık oranı 0,10' den küçük olması yapılan karşılaştırmaların tutarlı olduğunu gösterirken, bu oranın 0,10 ' den büyük olması karşılaştırmalarda bir tutarsızlığın olduğunu gösterir ve ikili karşılaştırma matrisin tekrar düzenlenmesi gerekir [21, 22]. Sonraki aşama ise alternatiflerin sıralanmasıdır. İkili karşılaştırma matrisin oluşturulabilmesi için, alt seviye kriterinin önceliği ile alternatiflerin ilgili kritere göre ağırlığı çarpılarak belirlenmesi gerekir. Herhangi bir alternatifin sırası tüm ağırlık değerleri toplamıdır. Bu işlem ile alternatiflerin önem dereceleri (sıralamaları) belirlenir. Karar verici bu önem derecelerine göre tercihini yapar [21].

\section{3. ÖNERILEN MODEL VE UYGULAMA (PROPOSED MODEL AND ITS APPLICATION)}

İstanbul'un ilçelerin afet yönetimi açısından stratejik önemlerinin belirlenmesinde gerekli veriler, İstanbul Büyükşehir Belediyesi (İBB) ve Japon Uluslararası İşbirliği Ajansı (JICA) [1] raporlarından alınmıştır. Kriterler ve hiyerarşi oluşturulma sürecinde ilgili literatürün yanı sıra, Jeoloji Mühendisliği, İnşaat Mühendisliği Geoteknik ve Yapı anabilim dalı ve afet yönetimi konusunda çalışmalar yapan akademisyenler ve arama kurtarma faaliyetleri yürüten uzmanlarıyla görüşmeler yapılmış, kriter ve alt kriterler bu görüşmeler neticesinde belirlenmiştir. Bu uzmanlarla ayrı ayrı anketler yapılmış, sonuçlar analiz edilmiştir. İlgili soru için genel bir kabul varsa uç değer atılarak bu genel kabul ikili kıyaslamanın değeri olarak kabul edilirken diğer kıyaslamalar için uzmanların ilgili soru için verdikleri cevapların geometrik ortalaması alınmıştır. Böylelikle sonucun aşırı uç değerlerden etkilenmesi önlenmiştir. Tablo Ek 1'de ana kriterlerin ikili kıyaslama matrisini göstermektedir. Diğer kıyaslamalar da benzer şekilde yapılmıştır. Elde

Tablo 1. Önem skalası (Importance scale)

\begin{tabular}{c|l}
\hline Önem skala değerleri & \multicolumn{1}{c}{ Tanımları } \\
\hline 1 & Karş1laştırılan her iki ölçütte eşit öneme sahiptir \\
3 & 1. ölçütü 2. ölçütten daha önemli olması durumu \\
5 & 1. ölçütün 2. ölçütten çok önemli olması durumu \\
7 & 1. ölçütün 2. ölçüte nazaran çok güçlü bir öneme sahip olması durumu \\
9 & 1. ölçütün 2. ölçüte nazaran mutlak üstün bir öneme sahip olması durumu \\
\hline $\mathbf{2 , 4 , 6 , 8}$ & Ara değerler \\
\hline
\end{tabular}


edilen bu ikili kıyaslamalar ve oluşturulan AHS yapısı, Super Decision 2.2.6 v [23] yazılımına girilmiş Windows XP işletim sistemine sahip özellikleri Intel ${ }^{\circledR}$ Core i3-2100 CPU, $3.10 \mathrm{GHz}, 3.42 \mathrm{~GB}$ of RAM olan bilgisayar kullanılarak ve bölgelerin afet yönetimi açısından önem ağırlıkları belirlenmiştir. Şekil 1'den de görüldüğü üzere dört seviyeli bir hiyerarşi kurulmuştur. İlk seviyede İstanbul'un ilçelerinin afet yönetimi açısından önem derecesinin bulunması amacı yer almaktadır. İkinci seviyede ana değerlendirme kriterleri bulunmaktadır. Bu kriterler: (1) Bölgenin bina stoku ile ilgili kriterler, (2) İlçenin coğrafi ve jeolojik özellikleri ile ilgili kriterler, (3) İlçenin altyapısını gösteren ölçütler, (4) İlçenin sosyoekonomik önemini gösteren ölçütler.

Bina Stoku Alt Kriterleri: İlgili literatürde [8, 24, 25] ve bütün deprem hasarlarının hesaplanması çalışmalarının [1] aşağıda yer alan üç alt kriteri dikkate aldığı görülmüş ve bu kriterler Bina Stoku alt kriterleri olarak düşünülmüştür: (1) Kat sayısı oranlarl (Ortalama), (2) Yapım Yllı (Ortalama), (3) Betonarme yapı türü oranı. Kat sayısı oranı yüksek olan, yaşlı binaları fazla olan ve deprem yönetmeliğine göre inşa edilmeyen (Betonarme oranıyla tespit edilmektedir) bina sayısı fazla olan bölge afet yönetimi açısından daha riskli olarak düşünülmüştür.

Coğrafi ve Jeolojik Önem Alt Kriterleri: Bu kriter üç alt kriterden oluşmaktadır. Bu alt kriterler: (1) Zemin slvılaşma oranı, (2) Bölgenin kapladı̆̆ alan, (3) Deprem merkez üssüne uzaklık. Zemin sıvılaşma oranı yüksek olan bölge afet yönetimi açısından risk teşkil etmektedir [1]. İlçelerin bir afette zemin sıvılaşma durumu değerlendirilirken, ilçelerin zeminlerinin ne kadarının yapay dolgu olduğu tespit edilmesi gerekir. $\mathrm{Bu}$ veri İstanbul Büyükşehir Belediyesi raporlarından elde edilmiştir. Alan olarak büyük bölgeler afet yönetimi açısından daha önemli olarak değerlendirilmektedir. Ayrıca deprem merkez üssüne yakın bölgeler afet yönetimi açısından daha riskli bölgelerdir.

Altyapı Alt Kriterleri: Bir bölgenin afet yönetimi açısından değerlendirilmesinde üçüncü kriter altyapı kriteridir ve bu kriter altı ayr1 alt kriterden oluşmaktadır: (1) Doğalgaz, (2) Şehir suyu ve kanalizasyon, (3) Elektrik, (4) Yol, (5) Acil durum yol tahliye yol uzunluğu, (6) Açı alan elde edilebilirlik. $\mathrm{Bu}$ ana kriter altındaki ilk üç kriter bölgenin doğalgaz, şehir suyu ve kanalizasyon ile elektrik şebekesi açısından önemlerini değerlendiren kriterlerdir. İstanbul'da gaz, elektrik, su, kanalizasyon gibi kentsel altyapı sistemleri özel ya da kamu kuruluşları tarafindan işletilmektedir. Su, elektrik ve gaz arzı toplumların gündelik yaşamlarını sürdürmede önemlidir ve afet yönetimi kapasitesi açısından da hayati öneme sahiptir [26, 27]. Yollar; ulaşım ve kentsel yaşamın sürdürülebilirliği açısından, en önemli altyapıdır. Altyapı ve iletişim hatlarının, yolların altına döşenmiş olması nedeniyle, yolların altyapı ve iletişim gibi fonksiyonları da bulunmaktadır [1]. Ayrıca yolların, hem yardımların ulaştırılmasında, hem de tahliye, yangınla mücadele ve sağlık hizmetlerinde önemli bir rolü bulunmaktadır. Yol ağının, mevcut yapısını ve fonksiyonunu kavramak, deprem afetinin önlenmesi ve yeniden yapılanmanın planlaması için son derece önemlidir. Yol ağ 1 fazla olan bölge afet yönetimi açısından diğer bölgelerden daha önemli olarak değerlendirilmiştir. Afet sırasında ve afet sonrasında depremzedelerin bölgeden tahliyesi ve yardımların bölgeye ulaştırılması, arama kurtarma ve enkaz kaldırma ekiplerinin bölgeye nakil edilmesi, yaralıların bölgeden yakın civardaki sağlık tesislerine taşınması acil durum yol kapasitesiyle ilgilidir ve afet yönetimi açısından büyük önem arz etmektedir [1]. Son alt kriter ise arazi elde edilebilirlilik ile ilgilidir. Diğer bir ifadeyle bu kriter ile bölgelerin afet sonrasında tahliye alanlarının oluşturulması değerlendirilmektedir [26, 27]. Bölgelerin tahliye alanı kapasitesi afet yönetimi açısından hayati önem arz etmektedir. Çünkü meydana gelebilecek artçı sarsintılardan kaynaklanacak can kayıpları bu tahliye alanları sayesinde azalmaktadır. Ayrıca deprem sonrası ortaya çıkabilecek salgın hastalık gibi ikincil afetlerin yaşanmasının da önüne geçilebilecektir. Ayrıca bu alanlar sayesinde acil müdahale ekiplerinin ve acil ihtiyaç malzemelerinin dağıtımının etkili bir şekilde yapılması sağlanabilir.

Sosyo-Ekonomik Önem Alt kriterleri: Modeldeki dördüncü kriter sosyo-ekonomik önem kriteridir ve bu kriter altı ayrı alt kriterden oluşmaktadır. Bu kriterler: (1) Nüfus, (2) Yerleşim binası yoğunluğu, (3) Ĕgitim tesislerinin yoğunluğu, (4) Sağlık tesislerinin yoğunluğu, (5) İdari (itfaiye, belediye vs.) tesislerinin yoğunluğu, (6) Ekonomik önem. Nüfus ve yerleşim binası açısından yoğun olan bölgelere afet yönetimi açısından öncelik verilmesi gerekmektedir [1, 26, 27]. Eğitim tesisleri afet yönetimi açısından önemlidir. Çünkü okullar gelecek nesiller için afet bilincinin topluma yayılmasında lokomotif görevi üstlenirler. Ayrıca okullar afetzedeler için toplanma noktaları olabilir. Bunlara ek olarak okul binaları eğer ciddi şekilde hasar görmemişlerse, geçici iskân ve barınma alanları olarak hizmet edebilirler. Sağlık tesisleri tıbbi müdahale için çok önemlidir. Hastalar deprem sırasında ve sonrasında sürekli tıbbi tedaviye ihtiyaç duyarlar. Tibbi tedavileri sekteye uğrayabilir ya da deprem olayından zarar görebilirler. Resmi binalar deprem yönetmeliği bina önem indeksine göre birinci derecede önemli binalardır ve bölgelerdeki bu binaların yoğunluğu o bölgenin afet yönetimi açısından önemini göstermektedir. Ekonomik önem değerlendirilmesinde ilçede bulunan işyeri ve istihdam sayıları dikkate alınmıştır. Her ilçede bulunan işyeri sayıları ve toplam istihdam sayılarına ilgili raporlardan ulaşılmıştır. Hiyerarşik yapıdaki son 


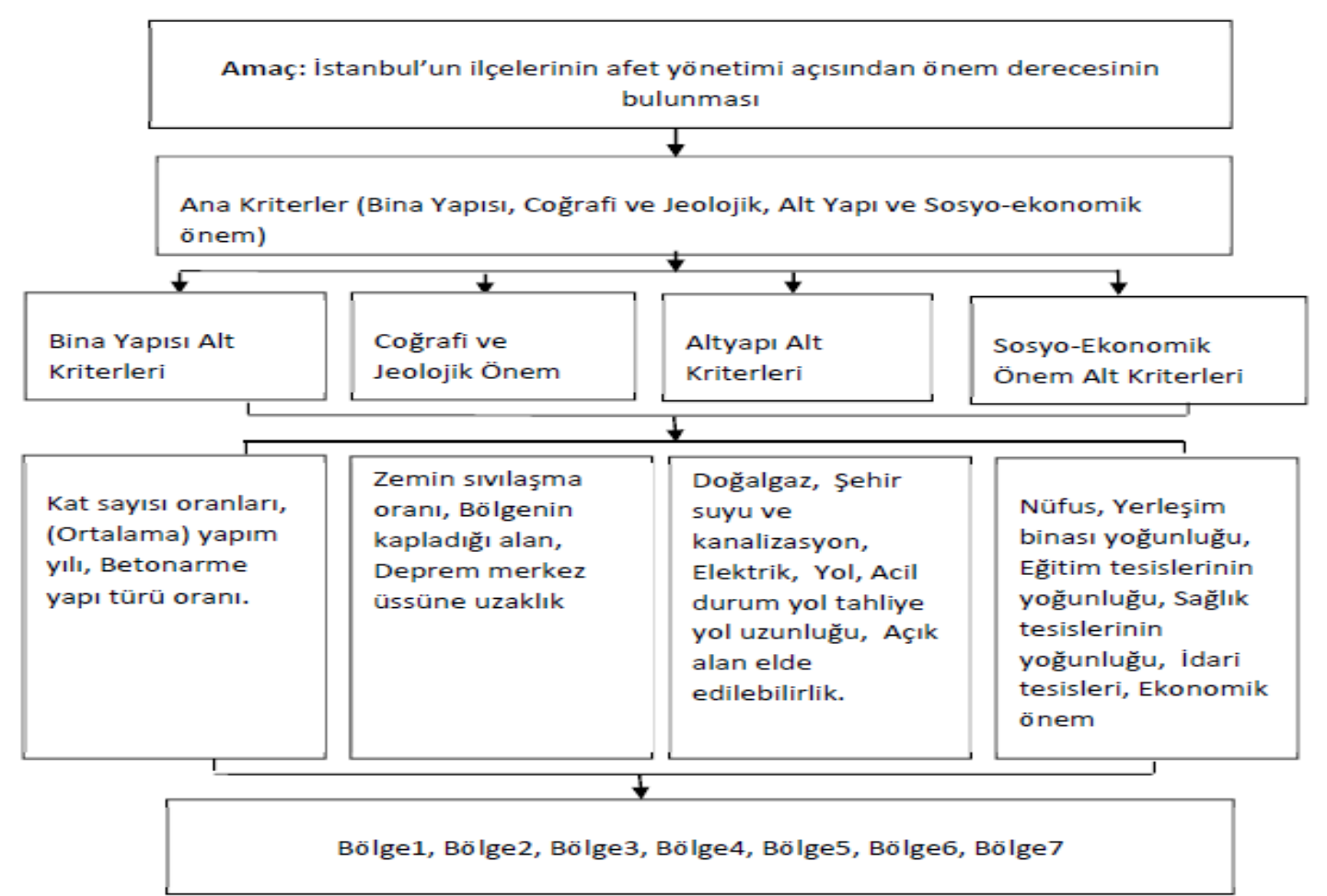

Şekil 1. Afet yönetimi önem indeksi karar hiyerarşisi (Decision hierarchy for disaster management importance index)

Tablo 2. Çalışma bölgesi (Study area)

\begin{tabular}{lcc}
\hline \multicolumn{1}{c}{ BölgeNo } & Açıklama & İlçeler \\
\hline 1. bölge & Tarihi Yarımada & Eminönü, Fatih, Beyoğlu \\
2. bölge & Avrupa-Marmara Sahili & Zeytinburnu, Bakırköy, Güngören, Bahçelievler, Avcılar \\
3. bölge & Avrupa-Boğaz & Beşiktaş, Kağıthane, Şişli, Sarıyer \\
4. bölge & Avrupa iç kesimler & Eyüp, G.O.Paşa, B.Paşa,Esenler, Bağcılar, K.çekmece \\
5. bölge & Asya- Boğaz & Üsküdar, Beykoz, Ümraniye \\
6. bölge & Asya-Marmara Sahili & Adalar, Kadıö̈y, Maltepe, Kartal,Pendik, Tuzla \\
7. bölge & Diğer & B.çekmece, Çatalca, Silivri \\
\hline
\end{tabular}

seviye alternatifleri göstermektedir. İstanbul'un 30 ilçesinin en alt seviyede yer alması düşünülmesine rağmen, AHS yönteminde bir seviyede yediden fazla elemanın yer alması kabul gören bir yaklaşım olmadığından ilçeler coğrafi yakınlıklarına göre yedi ayrı bölgeye ayrılmışlardır. Tablo 2'de bu bölgeler ve bölgelerin kapsadığı ilçeler görülmektedir. Örneğin birinci bölgede İstanbul'un tarihi yarımadasında yer alan Eminönü, Fatih ve Beyoğlu ilçeleri yer almaktadır.

\section{SONUÇLAR VE TARTIŞMA (RESULTS AND DISCUSSION)}

Çalışma sonucunda elde edilen sonuçlar aşağıdaki gibi suralanabilir. Tablo E2'de kriterlerin yerel ve global ağırlıkları görülebilir. Dört ana kriter grubu kendi aralarında kıyasladığında en önemli kriter grubunun "coğrafi ve jeolojik özellikler" 0,44544 ağırlıkla olduğu belirlenmiştir. İkinci sıra 0,34295 ağırlıkla bölgenin bina stokuyla ilgili olan kriterlerdir.
Sonrasinda ise sosyo-ekonomik kriterler 0,12593 ağırlıkla üçüncü sırada yer almaktadır. Bu dört ana kriter arasında son sırayı ise 0,08569 ağırlıkla alt yapı kriterlerinin aldığı saptanmıştır. Bölgenin coğrafi ve jeolojik yapısıyla ilgili kriterlerin kendi aralarında kıyaslanması sonucunda ise, en önemli kriterin 0,62592 ağırlıkla zemin sivılaşma potansiyeli kriteri, ikinci sırada ise 0,26001 ağırlıkla bölgenin deprem merkez üssüne uzakliğl kriteri, son sirada 0,11407 ağırlıkla ilgili bölgenin yüzölçümü kriteri olduğu görülmüştür. Bina stoku alt kriterlerinden betonarme oranı kriterinin 0,39256 ağırlıkla birinci, kat sayısı kriterinin 0,33705 ağırlıkla ikinci, yapım yılı kriterinin ise 0,27034 ağırlıkla üçüncü sırada olduğu ortaya çıkmıştır. Sosyo-ekonomik kriterler kendi aralarında kıyaslandığında ise siralamanın să̆lık binast yoğunluğu (0,38393), eğitim binast yoğunluğu (0,17877), kamu binası yoğunluğu $(0,15599)$, nüfus kriteri (0,122289), yerleşim binası yoğunluğu $(0,10613)$ ve son sirada da bölgenin ekonomik önemi kriteri $(0,05234)$ olduğu anlaşılmaktadır. Acil durum 
yol miktart ile yol miktarl kriterleri 0,24551 ve 0,21343 ağırlıkla diğer altyapı kriterlerinden önde oldukları, sonrasında elektrik $(0,18830)$, su ve kanalizasyon (0,16972), açık alan elde edilebilirlik $(0,10685)$ ve doğalgaz $(0,07619)$ kriterlerinin geldiği yapılan ikili karşılaştırmalar sonucu belirlenmiştir.

Sadece altyap kriterleri ile bölgelerin afet yönetimi açısından önem ağırlıklarının tespiti yapıldığında önem (risk) haritası oluşturulduğunda, Şekil 2'de yer alan harita elde edildi. Haritada görüldüğü üzere dördüncü bölge (Eyüp, Gaziosmanpaşa, Bayrampaşa, Esenler, Bağcılar, Küçükçekmece) 0,3110 ağırlıkla ilk sırada sonrasında da altıncı bölge (Adalar, Kadıköy, Maltepe, Kartal, Pendik, Tuzla) 0,252 ağırlığıyla gelmektedir. $\mathrm{Bu}$ bölgeleri sırasıyla ikinci, beşinci, üçüncü, yedinci ve birinci bölgeler izlemektedir. Bu sonuçlara göre altyapı açısından ilk sıradaki bölgelerde olabilecek olası bir hasar, bir afette bütün İstanbul'u etkileyebilecektir. Dolayısıyla afet yönetimi sisteminin güçlendirmesi ve bina güçlendirmeleri önem ağırlığı yüksek bölgelerde yapılması gerekebilecektir. Çünkü bu bölgelerde olabilecek bir yıkım şehrin altyapı kapasitesi (yol, acil yol, elektrik, su kanalizasyon vs.) önemli oranda azaltabilir. $\mathrm{Bu}$ ise afet sonrası arama-kurtarma faaliyetleri, yardımların ulaştırılması, barınma olanaklarının sağlanması gibi faaliyetlerin zamanında ve etkin yapılmasını etkileyecektir.

Ayrıca şehrin altyapısında meydana gelebilecek hasarlar ikincil afetlere yol açabilir (doğalgaz hatlarında patlamalar, yangınlar vs.). Haritadan çıkarılacak diğer önemli bir sonuç, bina güçlendirmeleri gibi afet riskini azaltacak faaliyetler Avrupa yakası için Avrupa-Marmara sahil ilçeleri ve Avrupa iç kesimler bölgesindeki ilçeler, Asya yakası içinde Asya-Marmara bölgesindeki ilçelerde yoğunlaştırılabilir. Böylelikle eldeki kısıtlı kaynaklar daha etkin kullanılmış olabilir. Diğer ana kriterleri ile bölgelerin afet yönetimi açısından önem ağırlıklarının tespitleri de yapıldı ve bunlarla bir önem (risk) haritaları Şekil Ek 1-2-3'te görülebilir. Şekil 3 ve Tablo 3 AHS sonuçlarını özetlemektedir. Sonuçlara göre afet yönetimi açısından en önemli bölge 0,2331 ağırlık ile birinci bölgedir. Bu bölge Eminönü, Fatih, Beyoğlu ilçelerini kapsamaktadır. İkinci sırada Eyüp, Gaziosmanpaşa, Bayrampaşa Esenler, Bağcılar, Küçükçekmece ilçelerini içeren 4. Bölge 0,1904 ağırlığı ile öne çıkmaktadır. Üçüncü sıradaki Zeytinburnu, Bakırköy, Güngören, Bahçelievler, Avcılar ilçelerinin afet yönetimi açısından önem indeksi 0,157'dir. Altıncı Bölge (Adalar, Kadıköy, Maltepe, Kartal, Pendik, Tuzla ilçeleri) 0,1388 önem ağırlığı ile dördüncü sırada yer almaktadır. Beşinci sırada Büyükçekmece, Çatalca, Silivri ilçelerinin yer aldığ 1 yedinci bölge bulunmaktadır. Altıncı ve yedinci sırada ise sirasıyla 0,0965 ağırlık ile 3. Bölge (Beşiktaş, Kağıthane, Şişli, Sarıyer) ve 0,0744 ağırlık ile Beşinci Bölge (Üsküdar, Beykoz, Ümraniye) yer almaktadır. Sonuçlar genel olarak değerlendirildiğinde; riski az (önem ağırlığı düşük) ilçelerin boğaz bölgesi ilçeleri olduğu, Marmara Denizi'ne yakın ilçelerin afet yönetimi açısından önem ağırlığının ise daha yüksek olduğu söylenebilir. Diğer önemli bir sonuçta ise Avrupa yakası ilçelerinin önem ağırlıklarının Asya yakası ilçelerine göre daha yüksek olduğudur.

Çalışmanın son aşamasında da ikili karşılaştırmalar tutarsızlık olup olmadığı araştırılmıştır. Tutarlılık indeksi yapılan ikili karşılaştırmalar arasındaki tutarsız değerlendirmeleri önlemek için son derece önemlidir. Tutarlılık indeksinin 0,1'den büyük çıkması ikili karşılaştırmalarda bir sorun olduğu anlamına gelir [28]. Çalışmadaki bütün tutarlılık indeks değerleri 0,1'den küçüktür. Dolayısıyla yapılan ikili kıyaslamalarda herhangi bir tutarsızlık görülmemektedir, diğer bir ifadeyle elde edilen sonuçlar sağlıklı olduğu söylenebilir.

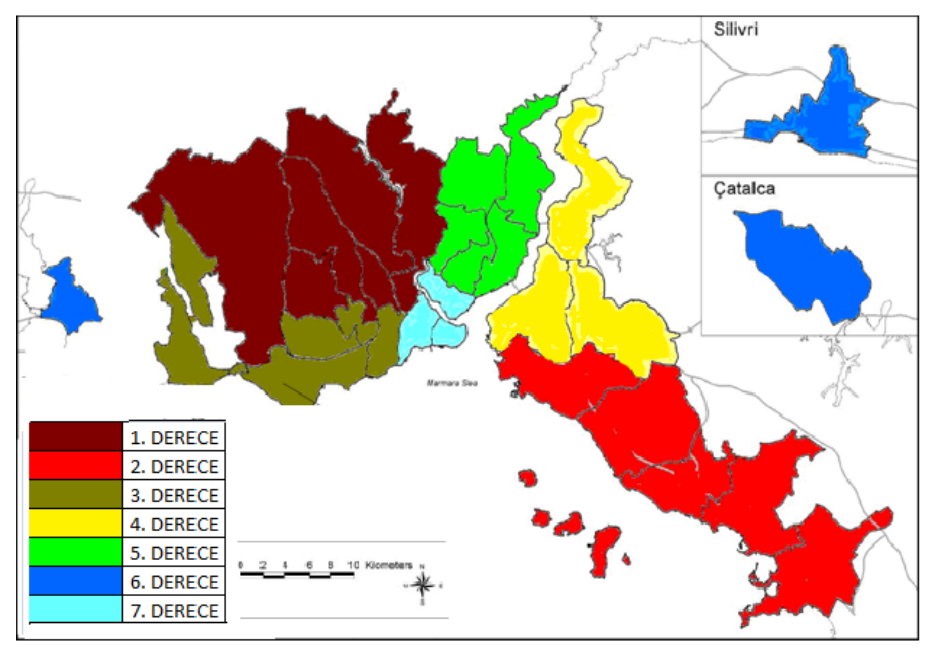

Şekil 2. Altyapı kriterleri açısından bölge önem dereceleri (Importance index according to infrastructure criteria) 
Tablo 3. İlçelerin afet yönetimi açısından önemleri (Importance weights of regions according to disaster managament)

\begin{tabular}{|l|l|l|l|l|l|}
\hline & Altyap1 & Bina Stoku & Sosyo-ekonomik & Coğ.rafi ve Jeolojik & Toplam \\
\hline Bölge 1 & 0,0405 & 0,2922 & 0,1178 & 0,2573 & 0,2331 \\
\hline Bölge 2 & 0,1333 & 0,1776 & 0,0941 & 0,1635 & 0,1570 \\
\hline Bölge 3 & 0,0921 & 0,1360 & 0,0817 & 0,0711 & 0,0965 \\
\hline Bölge 4 & 0,3110 & 0,1300 & 0,3276 & 0,1749 & 0,1904 \\
\hline Bölge 5 & 0,1194 & 0,1146 & 0,0745 & 0,0346 & 0,0744 \\
\hline Bölge 6 & 0,2520 & 0,1084 & 0,2830 & 0,0997 & 0,1388 \\
\hline Bölge 7 & 0,0518 & 0,0411 & 0,0213 & 0,1988 & 0,1098 \\
\hline
\end{tabular}

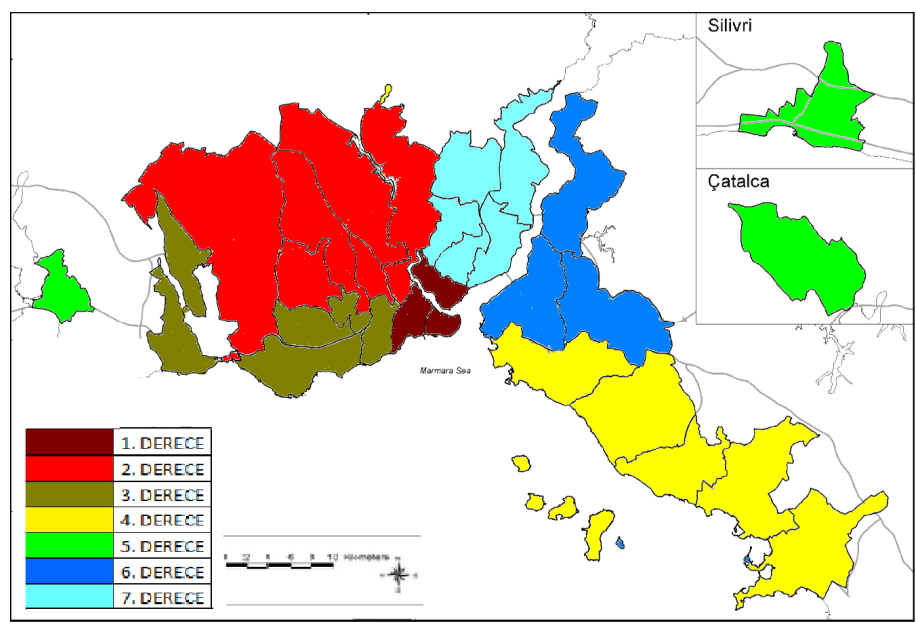

Şekil 3. İstanbul'un afet yönetimi açısından genel önem indeksi (ağırlığı) (General importance index (weights) for İstanbul)

\section{SONUÇLAR (CONCLUSIONS)}

İstanbul, coğrafi ve jeolojik özellikler, bina stoku, sosyo-ekonomik açıdan kırılganlığı ve altyapısındaki problemlerinden dolayı afete ve afetin olumsuz etkilerine çok açık bir konumda bulunmaktadır. Bu çalışmada İstanbul ilinin ilçeleri afet yönetimi açısından önem ağırlıkları AHS yöntemi ile ağırlıklandırılmıştır. Böylelikle afet risk haritaları oluşturulmuş, bina güçlendirmeleri gibi afet yönetimi yatırımlarına yön verecek bulgular elde edilmiştir. İstanbul'un ilçelerini afet yönetimi açısından AHS gibi çok nitelikli karar verme yöntemleri kullanılarak değerlendiren çalışmalara incelenen literatürde rastlanılmamıştır. Yapılan bu çalışma ile İstanbul'da risk içeren bölgeler tespit edilmiş bulunmaktadır. Ayrıca ilçelerin önem ağırlıkları deprem yönetmeliğinde belirtilen bina önem ağırlıklarılla çarpılarak ilçelerdeki bina türlerinin arasındaki önem ağırlıkları belirlenmiş̧tir. Elde edilen sonuçlara göre İstanbul'un Avrupa yakası genel olarak afet yönetimi açısından daha önemli olduğunu ortaya koymaktadır. Özellikle Avrupa-İç kesimler, Tarihi yarımada ve Avrupa Marmara Sahili bölgelerinde yapılacak olan afeti önleme yatırımları muhtemel depremin etkileri azaltacaktır. Asya yakası için yapılacak yatırımlarda da Asya-Marmara Sahili bölgesi ilçelerinde yapılması genel olarak İstanbul'un afet riskini azaltacaktır. Ayrıca İstanbul Boğazı'nın her iki yakasında yer alan bölgelerin afet yönetimi açısından riskinin az olduğu görülmüştür. Dolayısıyla özellikle yerleşim birimlerinin planlı şekilde bu bölgelere kaydırılması muhtemel afet riskini azaltacaktır. Çalışmada elde edilen sonuçlar İstanbul'un afet riskini artıracak noktaları gösterdiğinden, gerek şehir plancıları gerekse diğer karar vericiler için sistemde yapılacak iyileştirmelerde ve bina güçlendirmelerinde elde edilen bu sonuçlar yol gösterecektir.

\section{KAYNAKLAR (REFERENCES)}

1. Japan International Cooperation Agency (JICA) and Istanbul Metropolitan Municipality (IMM), The Study on a Disaster Prevention/Mitigation Basic Plan in Istanbul including Seismic Microzonation in the Republic of Turkey, Değerlendirme Raporu, Istanbul, 2002.

2. Parsons, T., "Recalculated Probability of $M \geq 7$ Earthquakes Beneath the Sea of Marmara, Turkey", Journal of Geophysical Research: Solid Earth (1978- 2012), Cilt 109, No B5, B5304, 2004.

3. Shah H., Bendimerad F. ve Stojanovski P., "Resource allocation in seismic risk mitigation", In Proceedings 10th world conference on earthquake engineering, Madrid, Spain, Cilt No 4, 6007-6011, 19-24 Temmuz 1992.

4. Dodo, A., Davidson, R., Xu, N., ve Nozick, L., "Application of regional earthquake mitigation 
optimization", Computers and Operations Research, Cilt 34, No 8, 2478-2494, 2007.

5. Vaziri, P., Davidson, R.A., Nozick, L.K., ve Hosseini, M., "Resource allocation for regional earthquake risk mitigation: a case study of Tehran, Iran", Natural Hazards, Cilt 53, No 3, 527-546, 2010.

6. Üstün, A.K, ve Barbarosoğlu, G., "Performance evaluation of Turkish disaster relief management system in 1999 earthquakes using data envelopment analysis." Natural Hazards, Cilt 75, No. 2, 1977-1996, 2015.

7. Üstün, A.K., ve Anagün, A.S., "Multi-objective mitigation budget allocation problem and solution approaches: The case of İstanbul", Computers \& Industrial Engineering, Cilt 81, 118-129, 2015.

8. Armas, I., "Multi-criteria Vulnerability Analysis to Earthquake Hazard of Bucharest, Romania", Natural hazards, Cilt 63, No. 2, 1129-1156, 2012.

9. Ayalew, L., Yamagishi, H., Marui, H., ve Kano, T., "Landslides in Sado Island of Japan: Part II. GIS-based Susceptibility Mapping with Comparisons of Results from Two Methods and Verifications", Engineering Geology, Cilt 81, No 4, 432-445, 2005.

10. Ercanoglu, M., Kasmer, N., ve Temiz O., "Adaptation and Comparison of Expert Opinion to Analytical Hierarchy Process for Landslide Susceptibility Mapping", Bulletin of Engineering Geology and the Environment, Cilt 67, No. 4, 565-578, 2008.

11. Wang, Y., Li, Z., Tang, Z., ve Zeng, G., "A GISBased Spatial Multi-Criteria Approach for Flood Risk Assessment in the Dongting Lake Region, Hunan, Central China", Water resources management, Cilt 25, No. 13, 3465-3484, 2011.

12. Levy, J.K., "Multiple Criteria Decision Making and Decision Support Systems for Flood Risk Management", Stochastic Environmental Research and Risk Assessment, Cilt 19, No. 6, 438-447, 2005.

13. Badri, M. A., "Combining the Analytic Hierarchy Process and Goal Programming for Global Facility Location-Allocation Problem", International Journal of Production Economics, Cilt 62, No 3, 237- 248, 1999.

14. Yang, T., and Kuo, C., "A Hierarchical AHP/DEA Methodology for the Facilities Layout Design Problem" European Journal of Operational Research, Cilt 147, No 1, 128-136, 2003.

15. Suresh, C., ve Kaparthi, S., "Flexible Automation Investments: A Synthesis of Two MultiObjective Modeling Approaches", Computers \& Industrial Engineering. Cilt 22, No 3, 257-272, 1992.

16. Güner, M., ve Önder, Y., "Konfeksiyon Üretiminde Temel Kriterlerin Hiyerarşik
Modellenmesi İle Üretilecek En Uygun Ürünün Belirlenmesi", Journal of the Faculty of Engineering and Architecture of Gazi University, Cilt 22, No 1, 73-79, 2007.

17. Dağdeviren, M., ve Eren, T., "Tedarikçi Firma Seçiminden Analitik Hiyerarşi Prosesi ve 0-1 Hedef Programlama Yöntemlerinin Kullanılması", Journal of the Faculty of Engineering and Architecture of Gazi University, Cilt 16, No 1, 41-52, 2001.

18. Dağdeviren, M., Dönmez, N. ve Kurt, M., "Bir İşletmede Tedarikçi Değerlendirme Süreci İçin Yeni Bir Model Tasarımı ve Uygulaması", Journal of the Faculty of Engineering and Architecture of Gazi University, Cilt 21, No 2, 247-255, 2006.

19. Arıkan, F., ve Küçükçe, Y. S., "Satın Alma Faaliyeti İçin Bir Tedarikçi Seçimi Değerlendirme Problemi ve Çözümü”, Journal of the Faculty of Engineering and Architecture of Gazi University, Cilt 27, No 2, 255-264, 2012.

20. Deshmukh, A. ve Millet, I., "Analytic Hierarchy Process Approach to Assessing the Risk of Management Fraud", The Journal of Applied Business Research, Cilt 15, No 1, 87-102, 1999.

21. Saaty, T. L., Fundamentals of Decision Making and Priority Theory with the Analytic Hierarchy Process, RWS Publications, Pittsburgh, PA, 2000.

22. Dağdeviren, M., Akay, D., ve Kurt, M., "İş Değerlendirme Sürecinde Analitik Hiyerarsi Prosesi ve Uygulamasi", Journal of the Faculty of Engineering and Architecture of Gazi University, Cilt 19, No 2, 131-138, 2004.

23. Internet: Super Decision, www.superdecisions.com, 2014.

24. Cutter, S.L., Boruff, B.J., Shirley, W.L., "Social Vulnerability to Environmental Hazards", Social science quarterly, Cilt 84, No. 2, 242-261, 2003.

25. Ebert A, Kerle N, ve Stein A., "Urban Social Vulnerability Assessment with Physical Proxies and Spatial Metrics Derived from Air- and Spaceborne Imagery and GIS Data", Natural Hazards, Cilt 48, No. 2, 275-294, 2009.

26. Carreño, M. L., Cardona, O.D., ve Barbat, A.H., "New Methodology for Urban Seismic Risk Assessment from A Holistic Perspective", Bulletin of earthquake engineering, Cilt 10, No. 2, 547-565, 2012.

27. Marulanda, M. C., Cardona, O. D., ve Barbat, A.H., "Robustness of The Holistic Seismic Risk Evaluation in Urban Centers Using the USRi", Natural hazards, Cilt 49, No. 3, 501-516, 2009.

28. Saaty, T. L., "Decision making for leaders. The analytic hierarchy process for decisions in a complex world. Vol. II, AHP Series", RWS Publications, Pittsburgh, 2001. 


\section{EKLER (APPENDIX)}

Tablo E1. Ana kriterlerin ikili kıyaslamaları (Pairwise comparison matrix of main criteria)

\begin{tabular}{l|l|l|l|l} 
& Altyap1 & Bina Stoğu & Sosyo-ekonomik & Coğ. ve Jeo. Özellikler \\
\hline Altyap1 & 1 & 0,244105 & 0,724795 & 0,231782 \\
\hline Bina Stoğu & 4,0966 & 1 & 4,3174 & 0,450349 \\
\hline Sosyo-ekonomik & 1,3797 & 0,231621 & 1 & 0,459158 \\
\hline Coğ. ve Jeo. Özellikler & 4,3144 & 2,2205 & 2,1779 & 1 \\
\hline
\end{tabular}

Tablo E2. Kriterlerin ağırlıkları (Weights of Criteria)

\begin{tabular}{|c|c|c|c|}
\hline Ana Kriterler & Ăğırlık & Alt Kriter & Ağırlık \\
\hline \multirow[t]{3}{*}{ Coğrafi ve jeolojik özellikler } & \multirow[t]{3}{*}{0,44544} & Zemin Sıvılaşma & 0,62592 \\
\hline & & Kapladığı Alan & 0,11407 \\
\hline & & $\begin{array}{l}\text { Deprem Merkez } \\
\text { Üssüne Uzaklık }\end{array}$ & 0,26001 \\
\hline \multirow[t]{3}{*}{ Bina stoğuyla } & \multirow[t]{3}{*}{0,34295} & Kat sayısı & 0,33705 \\
\hline & & Yapım Yilı & 0,27034 \\
\hline & & Betonarme Oranı & 0,39256 \\
\hline \multirow{6}{*}{ Sosyo-ekonomik kriterler } & \multirow[t]{6}{*}{0,12593} & Nüfus & 0,12229 \\
\hline & & $\begin{array}{l}\text { Yerleşim Binası } \\
\text { Yoğunluğu }\end{array}$ & 0,10613 \\
\hline & & Eğitim & 0,17877 \\
\hline & & Sağlık & 0,38393 \\
\hline & & İdari & 0,15599 \\
\hline & & Ekonomik önem & 0,05239 \\
\hline \multirow[t]{6}{*}{ Alt yapı kriterleri } & \multirow[t]{6}{*}{0,08569} & Doğalgaz & 0,07619 \\
\hline & & Su ve kanalizasyon & 0,16972 \\
\hline & & Elektrik & 0,1883 \\
\hline & & Yol & 0,21343 \\
\hline & & Acil durum yol & 0,24581 \\
\hline & & $\begin{array}{l}\text { Açık alan elde } \\
\text { edilebilrilik }\end{array}$ & 0,10685 \\
\hline
\end{tabular}

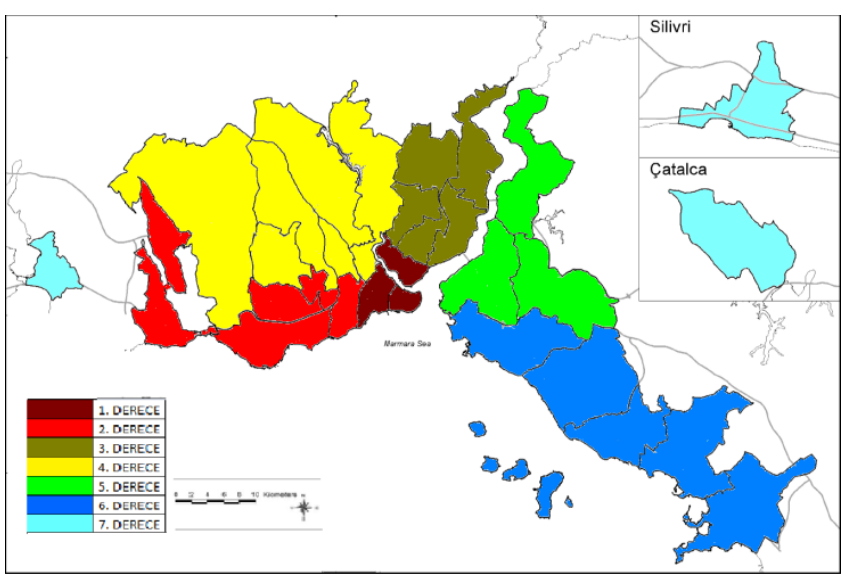

Şekil Ek 1. Bina stoğu kriterleri açısından bölge önem dereceleri (Importance index with respect to building inventory criteria) 


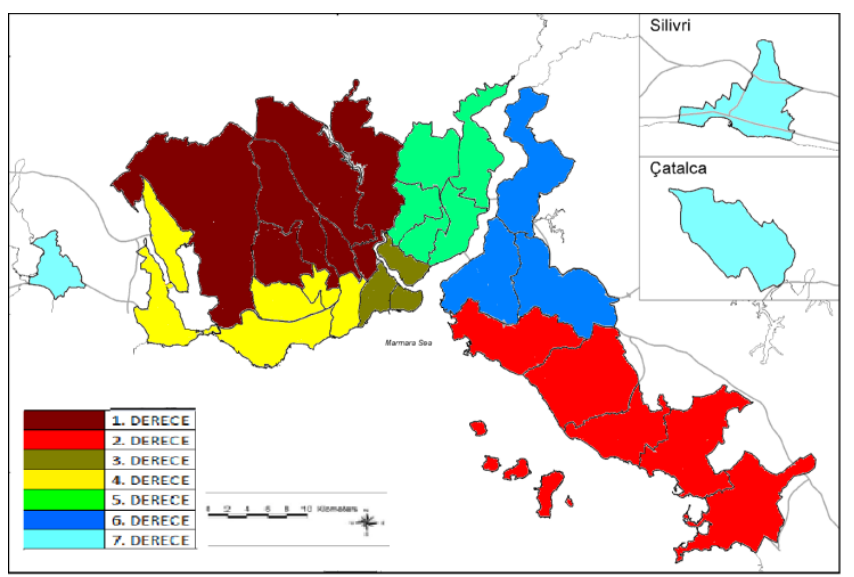

Şekil Ek 2. Sosyo-ekonomik kriterler açısından bölge önem dereceleri (Importance index according to socio-economic criteria)

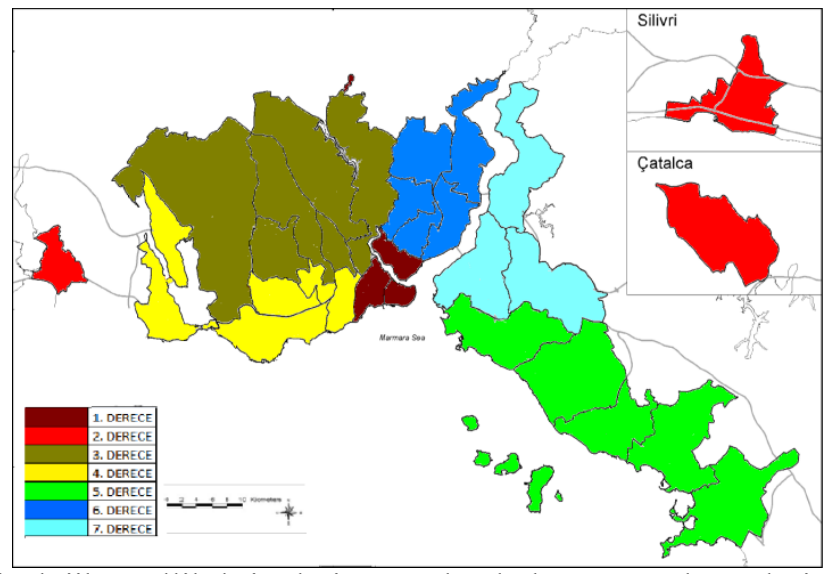

Şekil Ek 3. Coğrafi ve jeolojik özellik kriterleri açısından bölge önem dereceleri (Importance index according to geographical and geological importance criteria) 